\title{
Different Modes of Transmission and Containment Strategies for COVID-19
}

\author{
Sitaram Khadka ${ }^{1,2}$, Hamid Saeed ${ }^{2}$, Yogesh Bajgain², Janak Shahi², Tank Prasad Yadav², Ravi Prasad Gupta ${ }^{2}$
}

\section{Author Info:}

'Shree Birendra Hospital; Nepalese Army Institute of Health Sciences, Kathmandu-44600, Nepal

${ }^{2}$ Punjab University College of Pharmacy, University of the Punjab, Lahore-54000, Pakistan

\section{Corresponding Author:}

Sitaram Khadka

sitaramkhadka5693@gmail.com 00977-9851077589

\begin{abstract}
Coronavirus disease (COVID-19) is a respiratory infectious ailment caused by severe acute respiratory syndrome coronavirus-2 (SARS-CoV-2). The first outbreak of this disease occurred in China and declared a pandemic in a very short period of time. SARS-CoV-2 gets transmitted mainly through the respiratory tract by droplets or respiratory secretions, and by direct contact with the infected person as well as indirect contact through touching the contaminated surface accompanied by poor hygiene practice. Until the vaccine, therapeutic agent or any other treatment modality gets approved; contact tracing and management, social distancing, personal hygiene, respiratory etiquette, and environmental decontamination are the prime factors to be considered for transmission containment and hence for appropriate safety measures for COVID-19 which is possible with the support of social work from community level.
\end{abstract}

Keywords: Contagious; Containment strategies; COVID-19; Pandemic; SARS-CoV-2; Transmission

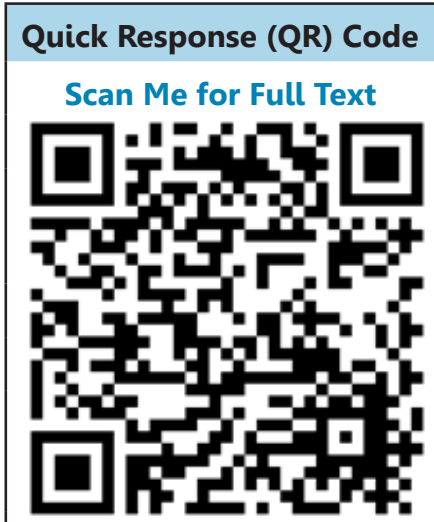

Article Info

Published Online: 24 May 2020

Received: 10 April 2020; $\quad$ Accepted: 23 May 2020,
How to cite this article in Vancouver Style?

Khadka S, Saeed H, Bajgain Y, Shahi J, Yadav TP, Gupta RP. Different Modes of Transmission and Containment Strategies for Covid-19. Europasian J Med Sci. 2020;2(Covid-19 Special Issue): 81-84. https://doi.org/10.46405/ejms.v2i2.50

Conflict of Interest: None Declared;

Disclaimer

Source of Support: Nil

Copyright: (c) 2020 by author(s). This is an open access article distributed under the terms of the Creative Commons Attribution International License 4.0. Which permits unrestricted use, distribution, and reproduction in any medium, provided the original work is properly cited.

\section{Publisher's Note}

The Europasian Journal of Medical Sciences (EJMS) remains neutral with regard to jurisdictional claims in published articles and institutional affiliations.

\section{BACKGROUND}

The COVID-19 is an infectious respiratory disease caused by a new coronavirus strain named as SARS-CoV-2, which first emerged in Wuhan, China, and reported to the world health organization (WHO) on 31 December 2019 as pneumonia of unknown source, later termed as COVID-19. ${ }^{1,2}$ The symptoms occur within two weeks after exposure that may range from mild type of fever, cough, headache, fatigue to shortness of breath, acute respiratory distress syndrome (ARDS), pneumonia, and shock. ${ }^{3}$ Thailand reported the first official case outside the epicentre on 13 January 2020. On 30 January 2020, the outbreak was announced as a public health emergency of international concern (PHEIC) and later declared a pandemic on 11 March 2020 by the WHO ${ }^{1}$ Around the globe, as of 09 May 2020, the total confirmed cases of COVID-19 stand at 3,767,744, including 259,593 deaths, where the United States of America has reported the maximum confirmed cases, i-e., 1,215,571 with a death toll of $67,146{ }^{4}$ 


\section{MECHANISMS AND MODES OF TRANSMISSION OF COVID-19}

SARS-CoV-2 belongs to the genera $\mathrm{D-coronaviruses,}$ an enveloped non-segmented positive-sense RNA virus, with genome sequence almost $96.2 \%$ similar to a bat coronavirus RaTG13 - implying bat as reservoir to SARS-CoV-2 virus. ${ }^{5}$ Thus, it is reasonable to deduce that SARS-CoV-2 might have transmitted from bat through an unspecified intermediary host to humans. The virus gains entry by binding to a host cell receptor followed by fusion with the cell membrane and lung epithelial cells as primary targets. The human-to-human transmission occurs by holding between the receptor-binding domain of virus spikes and the cellular receptor recognized as angiotensin-converting enzyme 2 (ACE2) receptor. ${ }^{6}$ The incubation period of SARSCoV-2 is approximately 3 to 7 days and COVID-19 is contagious in the course of latency period. It is extremely transmissible in humans, especially in the geriatrics and people with co-morbid conditions. ${ }^{7}$

Human-to-human transmission of SARS-CoV-2 takes place mainly through the respiratory route by droplets or respiratory secretions. ${ }^{8}$ Studies have also shown that even moderate viral protein concentrations in droplets gives virus the ability to expand exponentially - suggesting its high transmission capacity. ${ }^{9}$ The chances of droplet transmission increase with close contact, i-e., within 1 meter distance with COVID-19 positive people, which increases the propensity of viral entry via the mucosal membranes of the mouth, nose and eyes after exposure to potentially infective respiratory droplets.

Attempts have been made to isolate COVID-19 RNA in samples of air from places where COVID-19 patients were quarantined10, but the results are controversial, as some claim its presence and some otherwise. It is further argued that the detection of COVID-RNA in the environment using PCR test does not warrant the presence of a viable and transmissible virus, therefore, further detailed studies are required to confirm these claims. ${ }^{10}$ Though in some studies airborne transmission was not reported. ${ }^{11}$ succeeding dissemination by sneezing or coughing, droplets containing the coronavirus have been airborne, and it has been reported that the virus stands vital in that position until 3 hours when artificially nebulized as aerosol. ${ }^{1}$

COVID-19 spreads via both direct and indirect

Table 1: Different modes of transmission of COVID-19 and safety measures

\begin{tabular}{|l|l|}
\hline $\begin{array}{c}\text { Mode of } \\
\text { transmission }\end{array}$ & \multicolumn{1}{|c|}{ Characteristics } \\
\hline Droplet $^{10},{ }^{15}$ & $\begin{array}{l}\text { Droplets of different sizes: if }>5- \\
10 \mu \mathrm{m}, \text { called respiratory droplets, } \\
\text { and if }<5 \mu \mathrm{m}, \text { called droplet nuclei. }\end{array}$ \\
\hline
\end{tabular}

Microbes within droplet nuclei (particles $<5 \mu \mathrm{m}$ ) may contain in air Airborne ${ }^{1}{ }^{10}, 15$ for longer periods and transmitted to others over distances $>1 \mathrm{~m}$.

It is possible in specific cases where aerosols is generated.

Contact ${ }^{10}$

Close personal contact may help virus get entry though nose, mouth or eye.

Touching fomites in the environment around the infected person.

Fomites $^{13},{ }^{11}$ can transmit the virus through the mouth, nose or eye if touched with unclean hand

Feco-oral route $^{12}$

Virus has been detected in fecal swab

$\begin{array}{ll}\text { Mother to } & \text { No evidence is seen in caesarean }\end{array}$

\section{Safety measures}

Social distancing, limiting movement, wearing mask/ gloves/goggles, frequent hand washing through soap or using sanitizer, decontamination of suspected objects

Social distancing, limiting movement, wearing mask/ gloves/goggles, frequent hand washing through soap or using sanitizer, decontamination of suspected objects

Social distancing, limiting movement, wearing mask/ gloves/goggles, frequent hand washing through soap or using sanitizer, decontamination of suspected objects

Wearing gloves, frequent hand washing through soap or using sanitizer, decontamination of suspected objects

Limiting movement, wearing gloves, frequent hand washing through soap or using sanitizer, decontamination of suspected objects

Personal hygiene maintenance 
transmission, directly by contacting the infected person or indirectly by touching the contaminated surfaces in the immediate environment. SARSCoV-2 has also been isolated from patient's faecal swabs, indicating the possibility of transmission via multiple routes. ${ }^{12}$ There is no clinical evidence of COVID-19 transmission from mother to foetus in caesarean cases nor any such proof for vaginal birth6. Though, no scientific evidence exists that the survival of SARS-CoV-2 outside the body is comparable to Middle East respiratory syndrome (MERS), yet the claim is highly premature currently. Nonetheless, there are evidences that COVID-19 can spread via fomite contacts, e.g., washroom, escalators switch, taps, door knobs, utensils, etc. ${ }^{13}$ According to published reports, coronavirus can live for hours outside the host, such as aluminium, sterile sponges or latex surgical gloves, surging the opportunity for transmission via touch. ${ }^{14}$ The study suggested that the samples taken from toilet utensils, such as toilet bowl and sink were found positive, signifying it as a potential source of transmission, though the samples became negative post cleaning. ${ }^{11}$

In the same study, the authors claimed that the tested air samples were found negative, however, there could be a number of implicit limitations related to these findings, i-e., no viral culture to demonstrate viability, inconsistent methodology, small sample size, and small fraction to total air volume where the air exchange may have diluted the contamination. ${ }^{11}$ The $\mathrm{WHO}$ and the centre for disease control and prevention (CDC) advises health care workers and other staff to maintain 3-6 feet distance from the patient to prevent the transmission of the disease. Peak exhalation speeds may extend up to 33 to 100 feet per second, generating a cloud that can span around 23 to 27 feet. ${ }^{15}$ Table 1 shows the different modes of transmission and safety measures of COVID-19.

\section{TRANSMISSION CONTAINMENT STRATEGIES}

As contaminated fomites play a substantial role in the transmission of SARS-CoV-2, decontamination by repeated cleaning of the surface is a mandatory requirement to halt the transmission of virus to mitigate COVID-19 transmission. The better understanding of physiology of the host, pathogenesis, and epidemiological escalation of the disease are keys to achieve substantial improvements in disease remission and to prevent disease transmission to the vulnerable population ${ }^{15}$. The risk of nosocomial infection can be managed by inpatient control measures in hospitals by plan, do check, and act (PDCA) cycle ${ }^{16}$. The use of N95 or other surgical masks can help to control the spread of disease, which relies on the capacity of the mask to hold or restrict the high-momentum gas cloud emission. Protective and source control masks, and personal protective equipment (PPE) with the property to hold and protect the potential host from high-momentum multiphase turbulent gas clouds ejected during sneezing or coughing are essential protective gears to contain its spread ${ }^{15}$.

The contact tracing method of immediate scale up action by communities with trained individuals for identification of peoplewith travel history froma high risk area and people in contact with the suspected or infected individual, and their quarantine, test or isolation and treatment, if needed, in the nearby healthcare facility for transmission containment act as a key strategy to break the chain of spread of COVID-1917. The public health awareness program for preventive measures can be applied at the community as well as the central level for the transmission containment, and safety measures.

Herd immunity can be one of the strategies of safety measure that helps in transmission containment of disease, but as SARC-CoV- 2 has property of mutation, antibodies from a previous infection provide protection for only a short period of time, and its high risk of severity including death suggests to maintain social distancing from the time of high infection rate for maintenance of level of infection until vaccine develops ${ }^{18}$

Though not any therapeutic or prophylactic agents as well as treatment modalities have been approved, several antivirals and other drugs are being practiced to treat COVID-19, mostly focussing on the symptomatic treatment based on patient's status ${ }^{3}$. Drugs like hydroxychloroquine/ Azithromycin combination, ivermectin, oseltamivir, ganciclovir, Interferons, lopinavir/ritonavir combinations $^{19}$ and some other antibiotics are being practiced, taking care of their adverse events, along with the supportive care according to the WHO interim guidance for COVID management ${ }^{3}$. Remdesivir has recently been authorized by FDA for emergency use against COVID-1920. Different treatment modalities like convalescent plasma therapy have also been practiced with better safety profile. Several clinical trials are now underway to discover more specific and efficacious drugs, vaccines, and treatment modalities as well. 
Thus, for those taking care of COVID-19 patients and are vulnerable to contagion, droplet and contact; must adopt safety measures, such as social distancing, limiting movement, wearing mask/ gloves/goggles, frequent hand washing with soap or using sanitizer, and frequent decontamination practices along with apt measures to prevent airborne miasma in a clinical setting by adopting pre-emptive risk assessment and safety precautions to curtail disease transmission. ${ }^{10,21}$

\section{CONCLUSION}

The continuous global spread even after the passing of four months suggests the highly contagious nature of COVID-19 due to therapeutic qualm regarding the unavailability of an approved agent for treatment. Similarly, there is considerable ambiguity in the exact in depth understanding of the mode of its transmission and specific safety measures to prevent its spread. The consequential environmental contamination by patients with SARS-CoV-2 through respiratory droplets and faecal shedding suggests that the environment is one of the potential modes of transmission, therefore, there is a need for careful constancy to environmental hygiene practices. The utmost consideration must be given to personal hygiene such as frequent hand washing, respiratory etiquette, environmental decontamination, and social distancing for the containment of the disease. This is possible with the consistency of workforce from the community at the local to the central level within one umbrella, and of course social work from people has a pivotal role to accomplish such task.

\section{REFERENCE}

1. Khadka S, Hashmi FK, Usman M. Preventing COVID-19 in low- and middle-income countries. Drugs Ther Perspect. 2020;36(6):250-252. CrossRef

2. Naming the coronavirus disease (COVID-19) and the virus that causes it. WHO. Published 2020. Accessed May 18, 2020. Link

3. Clinical management of severe acute respiratory infection (SARI) when COVID-19 disease is suspected. WHO. Published 2020. Accessed May 21, 2020. LinkCoronavirus (COVID-19). WHO. Published 2020. Accessed May 21, 2020. Link

4. Zheng J. SARS-CoV-2: an emerging coronavirus that causes a global threat. Int J Biol Sci. 2020;16(10):16781685. CrossRef

5. Rothan HA, Byrareddy S. The epidemiology and pathogenesis of coronavirus disease (COVID-19) outbreak. J Autoimmun. 2020. CrossRef

6. Guo YR, Cao QD, Hong ZS, et al. The origin, transmission and clinical therapies on coronavirus disease 2019 (COVID-19) outbreak - an update on the status. Mil Med Res. 2020;7(1):11. CrossRef

7. Amgain K, Neupane S, Panthi L, Thapaliya P. Myths versus Truths regarding the Novel Coronavirus Disease (COVID-2019) Outbreak. J Karnali Acad Heal Sci. 2020;3(1).

8. Pastorino B, Touret F, Gilles $M$, de Lamballerie $X$, Charrel RN. Prolonged viability of SARS-CoV-2 in fomites. OSFPREPRINTS. 2020. CrossRef

9. Modes of transmission of virus causing COVID-19: implications for IPC precaution recommendations. WHO. Published 2020. Accessed May 3, 2020.

10. Ong SWX, Tan YK, Chia PY, Lee TH, Ng O T, Wong MSY, Marimuthu K. Air, surface environmental, and personal protective equipment contamination by severe acute respiratory syndrome coronavirus 2 (SARS-CoV-2) from a symptomatic patient. JAMA. 2020;323(16):1610-1612. CrossRef

11. Hindson J. COVID-19: faecal-oral transmission? Nat Rev Gastroenterol Hepatol. 2020. CrossRef

12. Cai J, Sun W, Huang J, Gamber M, Wu J, He G. Indirect Virus Transmission in Cluster of COVID-19 Cases, Wenzhou, China, 2020. Emerg Infect Dis. 2020;26(6). CrossRef

13. Qu G, Li X, Hu L, Jiang G. An Imperative Need for Research on the Role of Environmental Factors in Transmission of Novel Coronavirus (COVID-19). Environ Sci Technol. 2020;54(7):3730-3732. CrossRef

14. Bourouiba L. Turbulent gas clouds and respiratory pathogen emissions: potential implications for reducing transmission of COVID-19. JAMA. 2020. CrossRef

15. Amgain K, Rana T, Shrestha R, Shrestha S. Healthcare Associated Infections: Epidemiology, Contributing Factors and Control Measure in Developing Country. J Karnali Acad Heal Sci. 2019;2(3):161-165.

16. Contact Tracing. Part of a Multipronged Approach to Fight the COVID-19 Pandemic. CDC. Published 2020. Accessed May 8, 2020. Link

17. Gypsyamber D'Souza DD. What is Herd Immunity and How Can We Achieve It With COVID-19? JOHNS HOPKINS Bloomberg School of Public Health. Published 2020. Accessed May 8, 2020. Link

18. Kupferschmidt K, Cohen J. Race to find COVID-19 treatments accelerates. 2020;367(6485):1412-1413. CrossRef

19. FDA allows emergency use of anti-viral vaccine Remdesivir to treat COVID-19 patients. THE Economic Times. Published May 2, 2020. Link

20. Sajed AN, Amgain K. Corona Virus Disease (COVID-19) Outbreak and the Strategy for Prevention. Eur J Med Sci. 2020;2(1):1-4. 